\title{
Effect of the Normal Load on the Friction and Wear Behaviour of Nickel-based Alloys Ni-Cr-B-Si-C-W
}

\author{
C. Benoualia,*, M.N. Bachir beya, T. Sayah ${ }^{\mathrm{a}}$ \\ aLaboratory of Materials Technology, Faculty of Mechanical engineering and process engineering University of \\ Science and technology Houari Boumediene, B.P. 32 El Alia, Bab Ezzouar, Algiers, Algeria.
}

Keywords:

Friction

Wear

Normal Load

Nickel

Alloys

Tribometer

\section{* Corresponding author: \\ C. Benouali \\ Email:benoualichahrazed@gmail.com}

Received: 20 January 2020

Revised: 6 April 2020

Accepted: 9 September 2020

\begin{abstract}
A B S T R A C T
The purpose of this paper is to compare the influence of the normal load on the friction and wear behaviour of nickel-based alloys, which is use communally in the industry. We chose two samples of nickel-based alloys (NI-Cr-B-Si-C-W) elaborated by isostatic compression with a difference in their microstructure composition and quantity of micro constituent. The friction coefficient, the wear loss and the wear rate are evaluated using a tribometer (pin on disc) and a test bench created to reproduce the same industrial environment. Experiments showed that the applied normal load affects differently on the behaviour of the samples. The results conclude that the friction and wear resistance of the alloy do not just depend on the increase of the normal load but also on the distribution, the location and the morphology of the hard compounds formed in the alloys.
\end{abstract}

(C) 2020 Published by Faculty of Engineering

\section{INTRODUCTION}

In tribology, studies show that wear is a deterioration resulting from prolonged use during a contact of two solids. The friction is the ratio between the frictional force and the normal load [1]. It was observed by several authors [210] that the relation between these two tribological actions depends on interfacial conditions such as normal load, geometry, surface morphology, topography, chemical composition, system rigidity, temperature, relative humidity, lubrication, vibration and type of material.

According to researches, the Nickel based-alloys present excellent mechanical resistance, good surface stability, and resistance to corrosion or oxidation; it is employed in different application, automotive industry, aero engine and all fields of engineering [11]. Nickel-based alloy is widely used in tribological applications, their chemical composition differs in the components and the percentage used in the alloy.

Some works have been devoted to these alloys focusing mainly on the study of their mechanical properties or the evolution of their metallurgical structures under the effect of adding certain elements. Others [12-13] go to compare them and the nickel super alloys elaborated or obtained from mechanical pieces, they show the comportment of the 
friction and wear when hard layer are formed. Nickel based alloys is composed mainly of nickel (matrix), metallic $(\mathrm{Cr}, \mathrm{W})$ and no metallic (B, C and $\mathrm{Si}$ ) elements that favour the creation of the hard phases such as chromium carbide and chromium boride. It is used for sheet applications calling for oxidation and scaling resistance coupled with medium strength at high operating temperatures [13].

However, in our study we have chosen the parameter of normal load. [14] Reported that normal load are ones of major factors whose play significant role for the variation of friction and wear rate. These last ones make their study difficult in laboratory given the difficulty of reproducing the same industrial environment (wear and friction of mechanical parts in some mechanical devices). There are many methods of tribological test [15]. In order to overcome this problematic we designed a test bench on a horizontal lathe and we used a tribometer (disk-pin) to study and compare the tribological behaviour of two nickel-based alloys samples developed originally in [16-17].

In contrast, the previous works [16-17] proved that the quantity of the hard components formed and their composition impact on the behaviour of the alloys, without using a test bench, only a tribometer. The experiments are carried out in an atmospheric environment, to favour some mechanisms and to confirm the global interpretation on the load factor effect.

\section{MATERIALS AND METHODS}

\subsection{Alloys elaboration}

The Alloys made from pure metals in induction arc furnaces. The contents are: nickel bases, chromium (25\% in at. \%), carbon $(3,5 \%$ in at. $\%$ ), boride (5 \% in at. \%), silicium (3\% in at. \%), and tungsten (3,5\% in at. \%) [16-17].

\subsection{Thermal Analysis}

The alloys heated in arc furnace under argon atmosphere then they are solidified slowly in a differential thermal analysis device (ATDNETSCH), controlled by swiping of argon The speed of cooling is kept constant at $5^{\circ} \mathrm{C} / \mathrm{mm}$ in order to get coarse and unchanged phases which can be easily characterised.

\subsection{Physics-Chemical alloys characterisation}

The microstructure of the samples is observed using scanning electronic microscope (jeol JSM6360) coupled to an analyser EDAX.

A specific analysis of phases has been realised with electron microprobe (CAMECA-SX50) on perfectly polished samples. A particular attention has been given to the measurement of the weight components (Table 1).

Table 1. Chemical compositions and transformation temperatures of the alloys phases.

\begin{tabular}{|c|c|c|c|c|c|c|c|c|c|c|}
\hline \multirow{3}{*}{$\begin{array}{c}\text { Alloy } \\
1\end{array}$} & \multicolumn{5}{|c|}{ Chemical composition at.\% } & \multirow{2}{*}{$\begin{array}{c}\text { Formed } \\
\text { phases }\end{array}$} & \multirow{2}{*}{\multicolumn{4}{|c|}{$\begin{array}{c}\text { Temperatures } \\
\text { of transformation }\left({ }^{\circ} \mathrm{C}\right)\end{array}$}} \\
\hline & $\mathrm{C}$ & $\mathrm{Si}$ & B & $\mathrm{Cr}$ & W & & & & & \\
\hline & 3.5 & 3.0 & 7.2 & 25 & 3.5 & $\begin{array}{c}{\left[\mathrm{M}_{7} \mathrm{C}_{3}\right]} \\
{\left[\mathrm{M}_{7} \mathrm{C}_{3}-\mathrm{Ni}(\mathrm{g})\right]}\end{array}$ & 1270 & 1250 & 1045 & 1000 \\
\hline 2 & 4.8 & 5.0 & 5.0 & 25 & 3.5 & $\begin{array}{c}{[\mathrm{Ni}(\mathrm{g})-} \\
\left.\mathrm{M}_{5} \mathrm{~B}_{3}\right] \\
{\left[\mathrm{Ni}(\mathrm{g})-\mathrm{Ni}_{3} \mathrm{~B}\right]}\end{array}$ & 1300 & 1270 & 1050 & 1010 \\
\hline
\end{tabular}

\subsection{Tribological test}

In this study, we have designed a small device, to reproduce the same real condition in the test bench, which is as follows, an around pipe in which houses a compression spring slide to control the variation of the normal load and a rod round bore at the extremity to case the pin(sample). This device can slide on rotating horizontal area (a disc made of steel) with a diameter equal to $210 \mathrm{~mm}$ fixed by the chuck on an horizontal lath, the material used for the disc and the pin are respectively XC48 and two different nickel-based alloys (Ni-Cr-BSi-C-W ).

Regarding the calibration, it was performed on a compression Machin of mechanic tests using different loads $50 \mathrm{~N}, 80 \mathrm{~N}$ then $100 \mathrm{~N}$, for which we made a graduations on the round as shown Fig. 1b, to control the change of loads in the experiment.

The Contact surface was polished with abrasive paper graded between 400 and 2000 .This experiment was conducted in an atmospheric environment and dry sliding with a constant sliding speed of $0.126 \mathrm{~m} / \mathrm{s}$. 


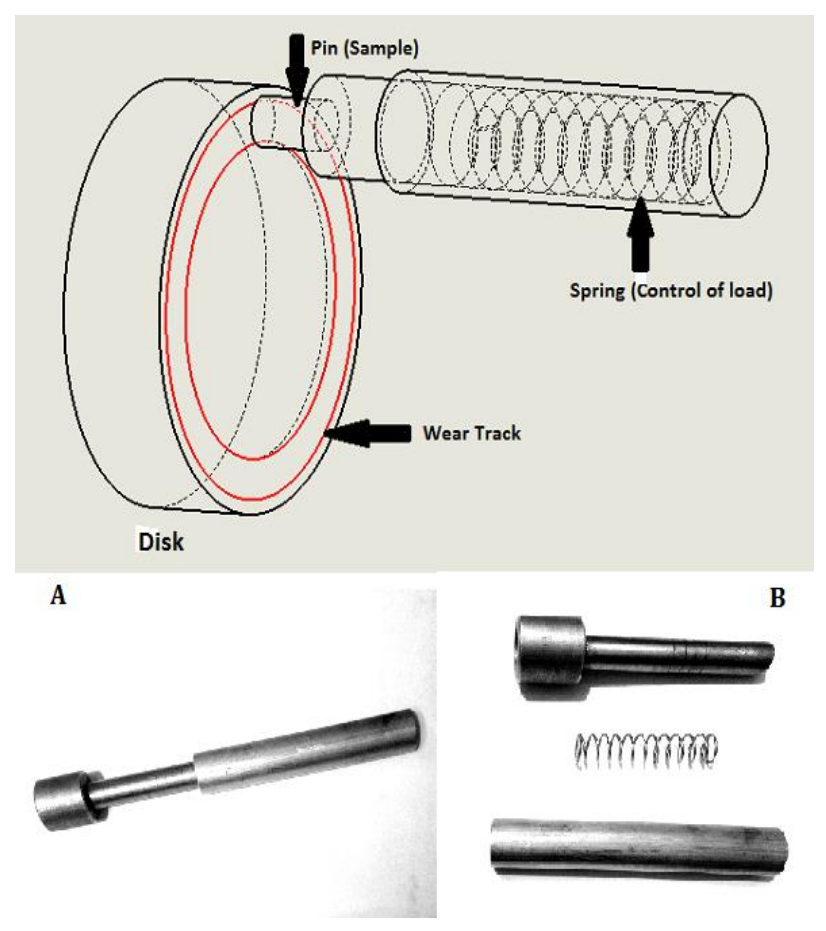

Fig. 1. Schematic of the test bench.

On the test bench we applied to a variation of normal loads on the two pins (two alloys) using $50 \mathrm{~N}, 80 \mathrm{~N}$ then $100 \mathrm{~N}$ and the time of acquisition is $30 \mathrm{~min}$ for each load, we measured the weight on the end of each 30min. On the tribometer type pin-disk we have reissued the same operation done on the test bench to have the friction coefficient for each pin in each load. We note that the pin (alloys) is fixed and a ball rotate on the alloys, the ball have the same material as the disc in the test bench.

\section{EXPERIMENT RESULTS AND DISCUTIONS}

\subsection{Quantitative analysis}

The Table 2 shows the quantitative analysis in at. \% of simples in the $\mathrm{Ni}(\gamma)$ solid solution and the phases for the standard alloys selected $(\mathrm{M}=\mathrm{Cr}, \mathrm{Ni}, \mathrm{W})$ obtained by EDS analyses.

Table 2. Quantitative analysis in at. \% of observed phases for standard alloys selected.

\begin{tabular}{ccccccc}
\hline Phases & $\mathrm{Ni}$ & $\mathrm{Si}$ & $\mathrm{B}$ & $\mathrm{C}$ & $\mathrm{Cr}$ & $\mathrm{W}$ \\
\hline $\mathrm{Ni}(\gamma)$ & 77.0 & 2.0 & $<1$ & - & 18.5 & 2.0 \\
$\mathrm{M}_{7} \mathrm{C}_{3}$ & 3.0 & $<0.1$ & $<2$ & 28.0 & 65.0 & 2.2 \\
$\mathrm{M}_{5} \mathrm{~B}_{3}$ & 5 & $<0.01$ & 35.0 & $<2$ & 52.0 & 6 \\
\hline
\end{tabular}
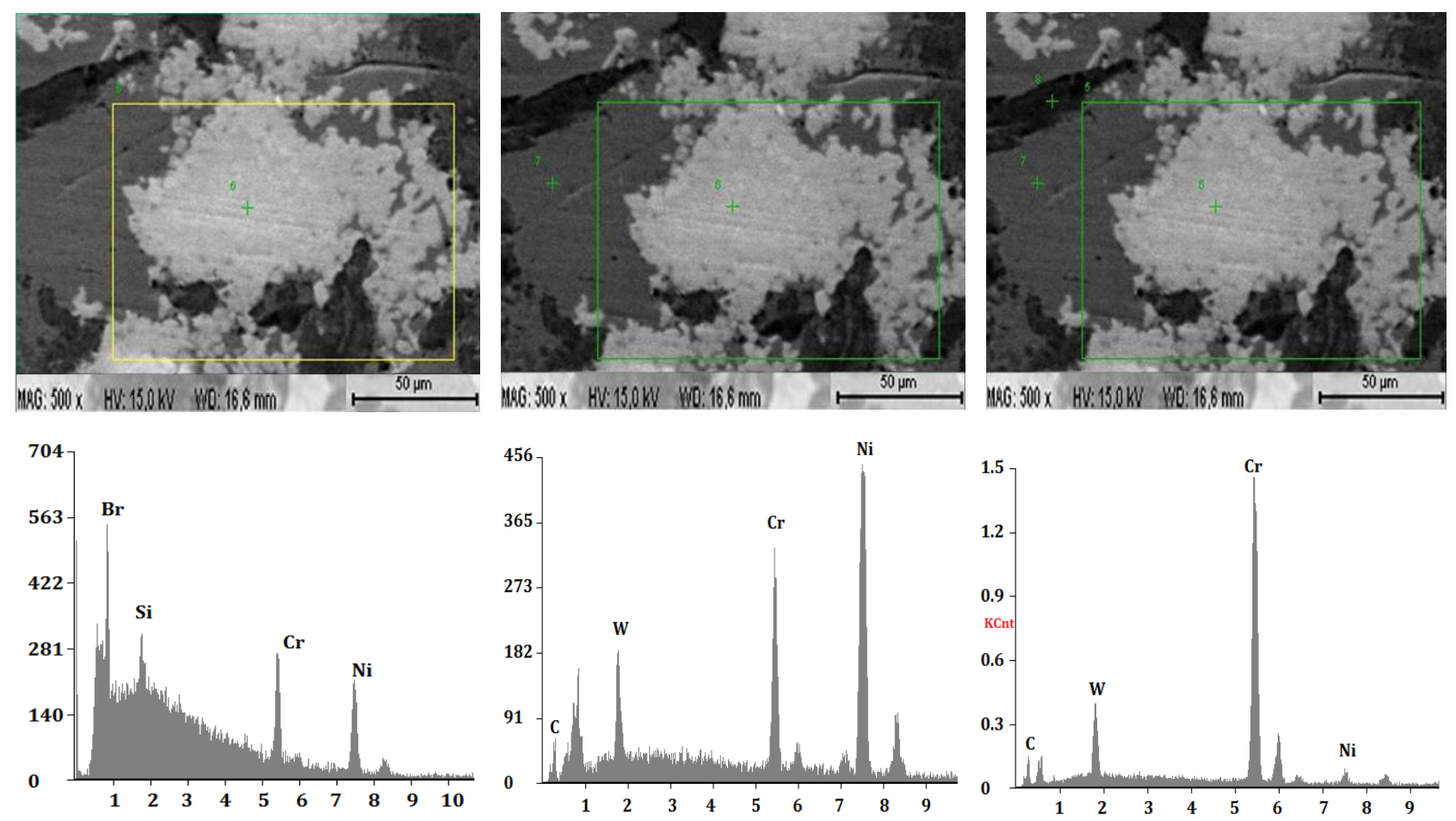

(a) 


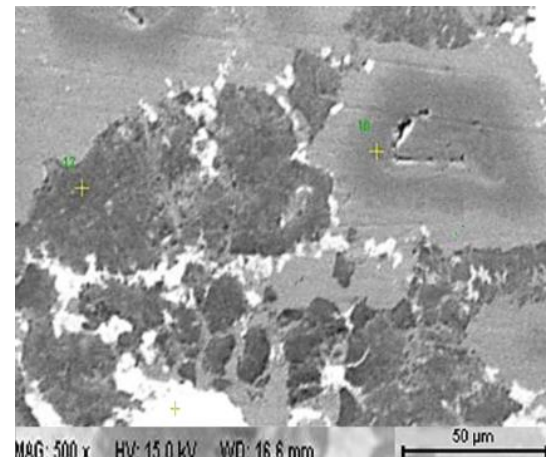

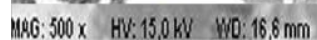

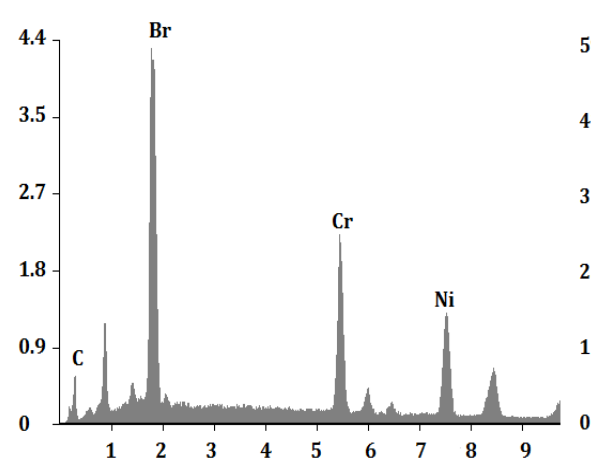

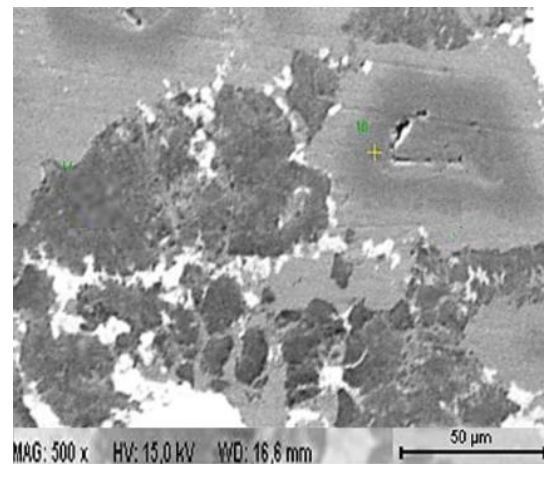

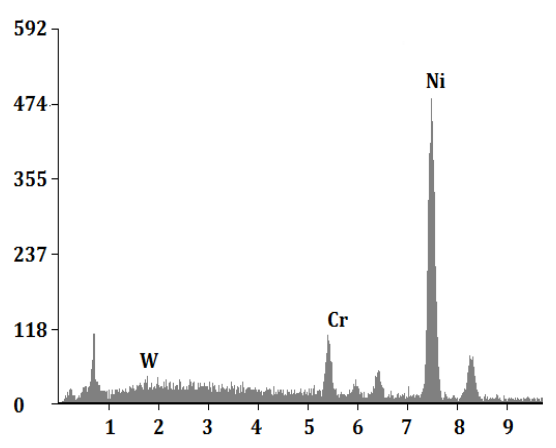

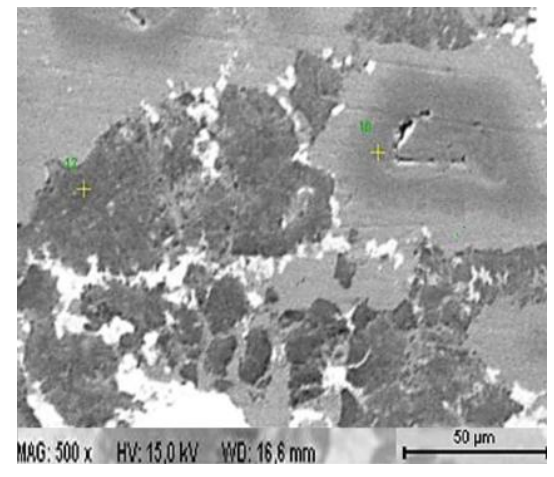

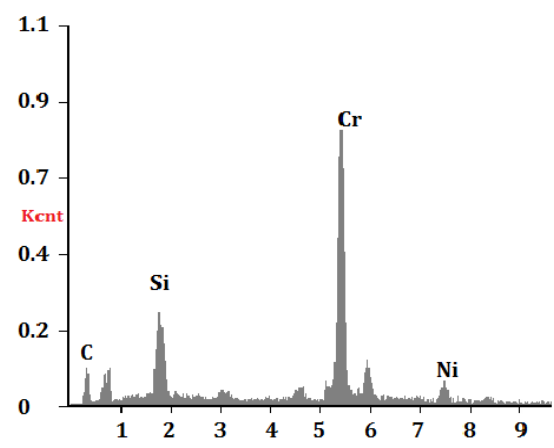

(b)

Fig. 2. The EDS analysis of the different phases: $\left(M_{5} B_{3}\right)$ phase, $\left(M_{7} C_{3}\right)$ phase and (Ni $\left.(\gamma)\right)$ phase: (a) Alloy 1 , (b) Alloy2.
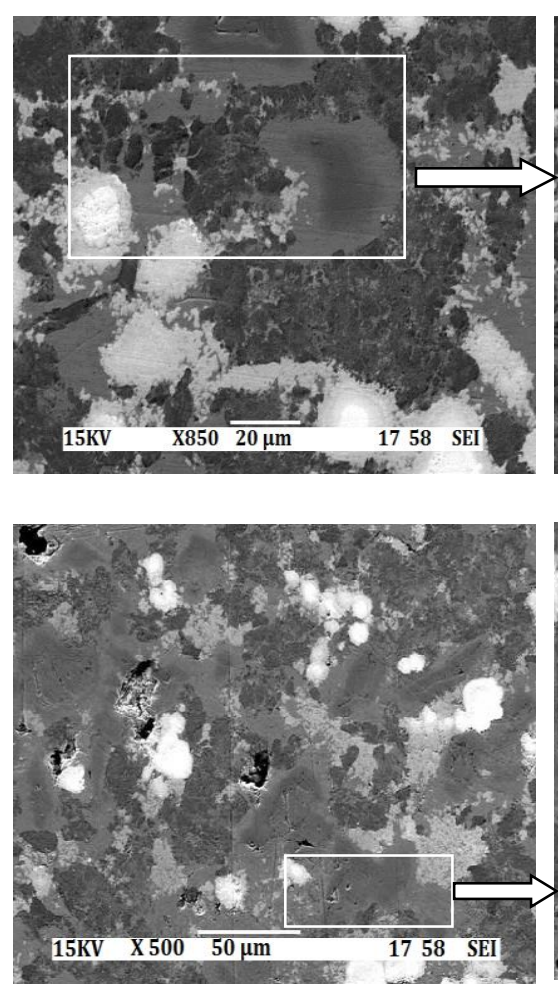

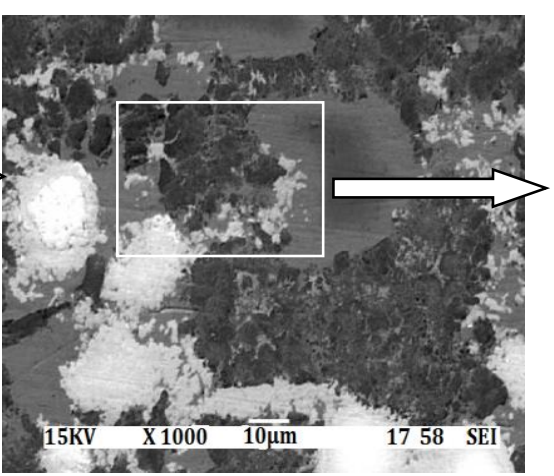

(a)

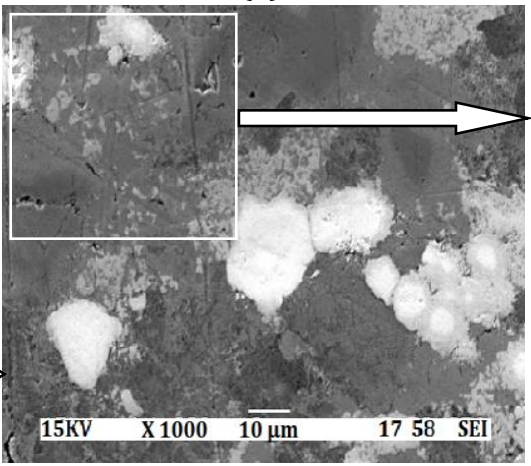

(b)
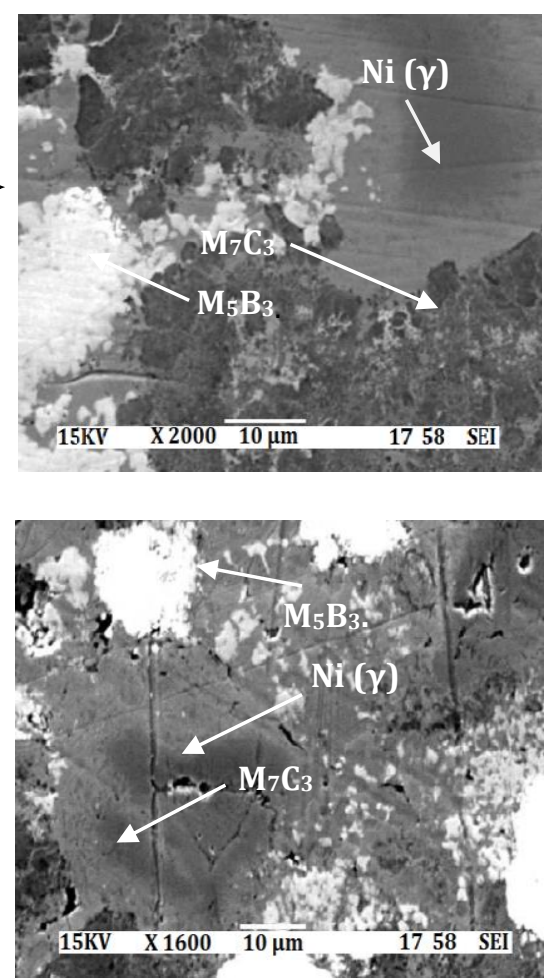

Fig. 3. Microstructures of the study alloys: (a) Alloy 1, (b) Alloy 2. 


\subsection{Alloys microstructure}

The alloys present sufficiently coarse structures enough to being accurately analysed by electron Microprobe and allow following the chemical component repair in various phases. The complex microstructure of alloys is presented in the (Fig. 3), the alloys show three phases, the $\mathrm{Ni}(\gamma)$ matrix is in light colour, the carbide $\mathrm{M}_{7} \mathrm{C}_{3}$ phase is in the black and the white colour for the Boride $\mathrm{M}_{5} \mathrm{~B}_{3}$ phases, which is confirmed with the EDS analysis (Fig. 2).

The chromium carbide $\mathrm{M}_{7} \mathrm{C}_{3}$ crystallises at a $1270{ }^{\circ} \mathrm{C}$ and $1300{ }^{\circ} \mathrm{C}$ successively in alloy 1 and 2 , the chromium boride $\mathrm{M}_{5} \mathrm{~B}_{3}$ crystallises in the eutectic phase at $1050{ }^{\circ} \mathrm{C}$ and in the end of the solidification operation forms the eutectic $\mathrm{Ni}(\gamma)+\mathrm{M}_{5} \mathrm{~B}_{3}$ at $1000{ }^{\circ} \mathrm{C}[11]$.

\subsection{The influence of normal load on the friction coefficient}

The Fig. 4 shows the variation of the friction coefficient with the sliding distance at different normal loads of $50 \mathrm{~N}, 80 \mathrm{~N}$ and $100 \mathrm{~N}$, where the sliding speed is $0.126 \mathrm{~m} / \mathrm{s}$. The graph consists of two regimes: the transitional and the permanent regime.

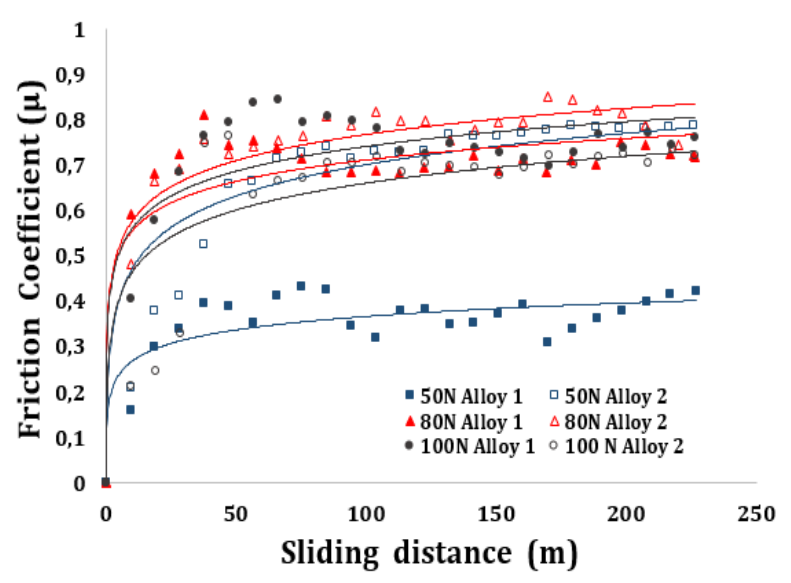

Fig. 4. Variation of friction coefficient with the variation of normal load $50 \mathrm{~N}, 80 \mathrm{~N}$ and $100 \mathrm{~N}$. Sliding speed $=0.126 \mathrm{~m} / \mathrm{s}$.

These curves show a rapid increase of friction coefficient in the transitional regime between 0 and $100 \mathrm{~m}$ followed by stability in the Permanent regime corresponding to a stabilised wear in each normal load for both of the alloys. On the other hand, we note the same behaviour for alloys 1 under the load of $50 \mathrm{~N}$ with a lower coefficient of friction.During the initial period, the contact is metallic in nature, as well as the transfers. There are very little wear debris (tiny area of contact) in the contact. The contact area increases, more debris are formed and the friction conditions become stable, which facilitates the sliding between the two surfaces and the coefficient of friction reaches an almost constant value.

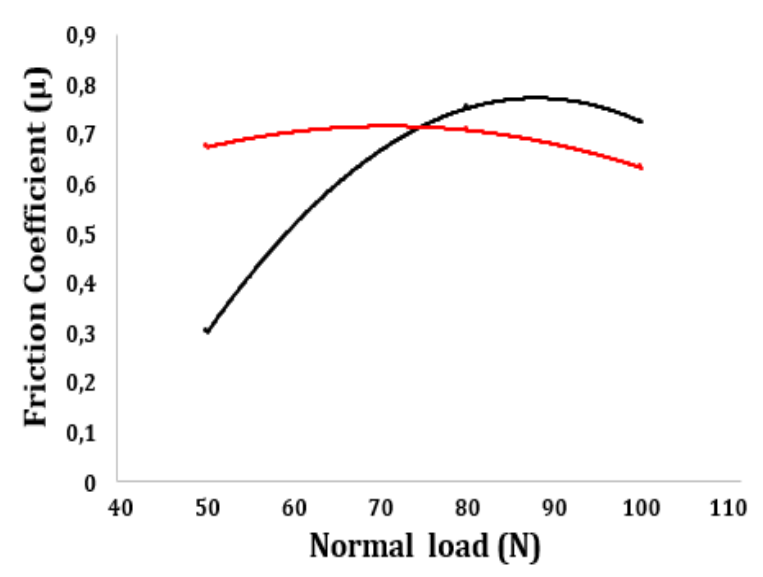

Fig. 5. Evolution of friction coefficient $\mu$ with the variation of normal load.

The comparison of the friction coefficient with the variation of the normal load is presented in the Fig. 5 the curves in this figure represent the behaviour of the alloys in contact with the surface (pin-disk), in the transient phase (break-in), the increase of the normal load leads to an increase of the friction coefficient for the alloy 1 . Moreover, the friction coefficient of the alloy 2 is relatively constant at the beginning of the tests. This difference is due to the emergence of the hard compounds in the ductile matrix $\mathrm{Ni}(\gamma)$ of each alloy, which confirms the result in the Fig. 4.

\subsection{The influence of normal load on the wear behaviour}

Figure 6 shows the histogram of the wear loss for both alloys in the test bench and on the tribometer. Furthermore, we note that the wear of alloy 1 increase with the increase of the normal charge, same Remarque for the alloy 2 . This increase is due to multiple damages with zones deformed by indentations, and grooves with lateral bulges associated with abductions of matter. In fact, the asperities of the two surfaces interpenetrate under the influence of the normal load. This detachment of material results from the friction of the rough surfaces (pin-disc) in contact. 


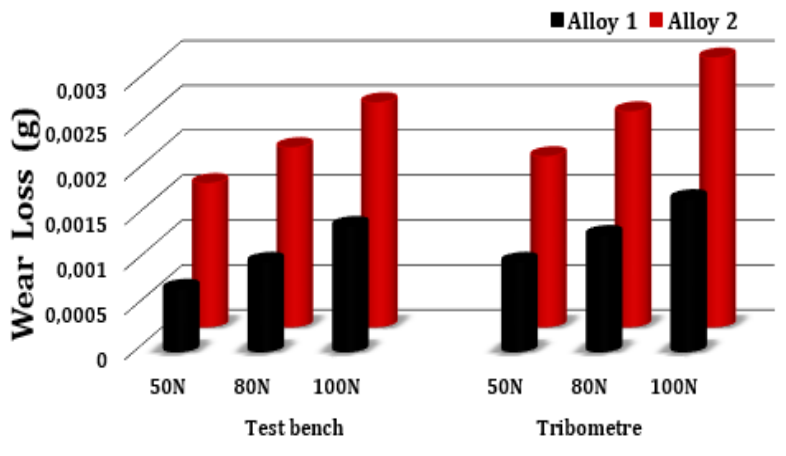

Nomal load (N)

Fig. 6. Evolution of wear loss as function of normal load of the Alloy 1 and Alloy 2 in the test bench and the tribometer.

We note that the loss of mass for alloy 1 is lower than it is for alloy 2 , and this observation is valid even by increasing the load $(50 \mathrm{~N}, 80 \mathrm{~N}$ and 100 $\mathrm{N})$. This result remains identical for both tests.

We represent the wear rate of each alloy with the variation of the normal load in the test bench and the tribometer.

The wear of the $\mathrm{Ni}(\gamma)$ ductile matrix as test progress, favours the emergence of the $\mathrm{M}_{5} \mathrm{~B}_{3}$, $\mathrm{M}_{7} \mathrm{C}_{3}$, hard phases existing in the alloy's microstructure that goes to the second regime of stabilised wear .The results show the wear of alloy 1 after 30 minutes of test for each load in which the hard compounds (borides) are emphasised. The second alloy has a metallurgical structure mainly formed of ductile $\mathrm{Ni}(\gamma)$ and some of hard compounds $\mathrm{M}_{5} \mathrm{~B}_{3}, \mathrm{M}_{7} \mathrm{C}_{3}$. The alloy 1 present a lower wear rate at the beginning of the tests, therefore a high abrasion resistance at the beginning this wear rate reverses after $100 \mathrm{~m}$ of the sliding distance (rolling phase), compared to the alloy 2 which is quasi-liner throughout the test period (Fig. 7).

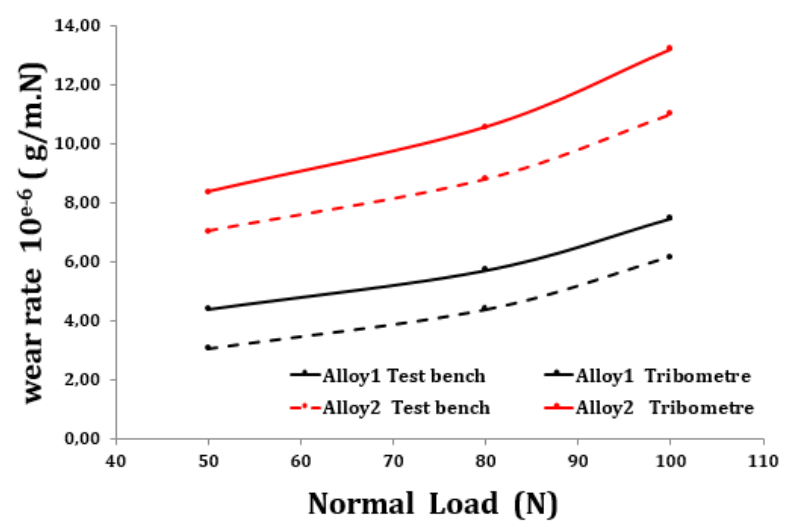

Fig. 7. Wear rate versus the normal load in the test bench and the tribometer for alloy 1 and alloy 2 .
This is due to the constant presence of hard phases renewed in the homogeneous structure of the alloy and at the end of the test has a polished and regular shape. Abrasive wear is the damage on a surface, which appears due to the motion relative to the surface of either harder asperities or perhaps hard inclusions trapped at the interface [18]. When the size of the abrasive particles increase, the wear is more pronounced than the one obtained by low abrasive particles. This is observed in the beginning of the test as well as the end of the wear test.

\subsection{Wear mechanism of alloys}

We have identified the wear track of the alloys in the Figs. 8 and 9. This shows the worn surface morphology for both alloys under two different loads $50 \mathrm{~N}$ and $100 \mathrm{~N}$ in the tribometer.

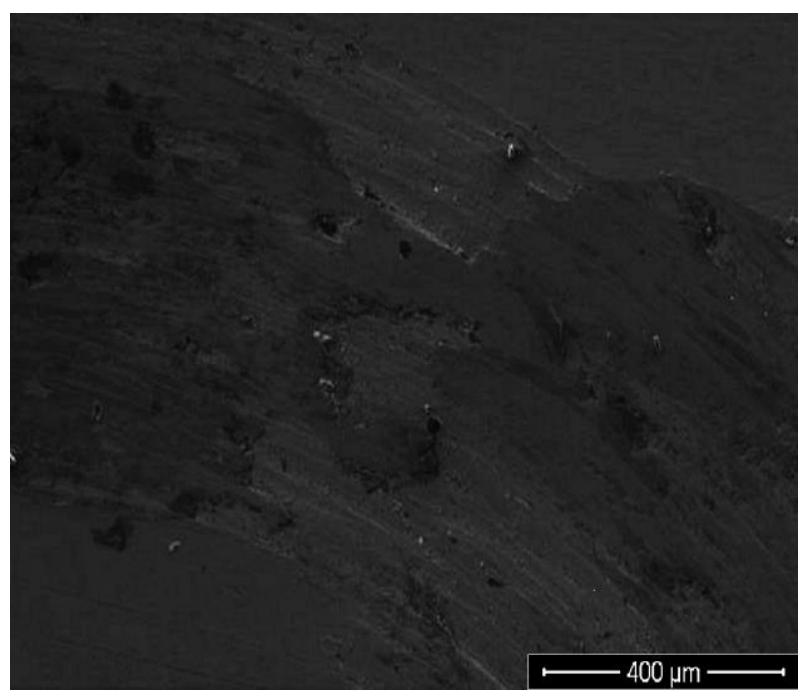

(a)

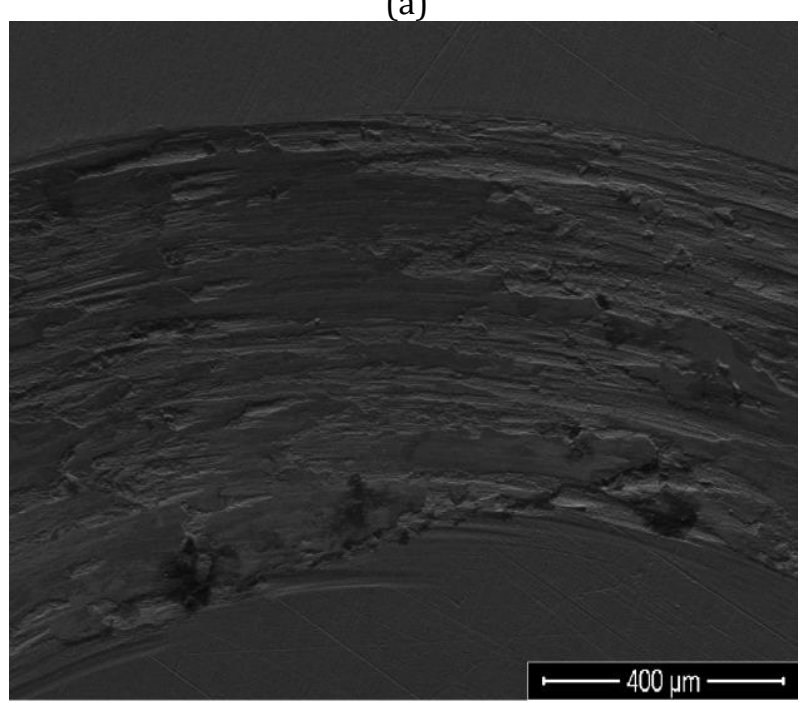

(b)

Fig. 8. Worn surface morphology of Alloy (1) under normal load: (a) $50 \mathrm{~N}$, and (b) $100 \mathrm{~N}$. 


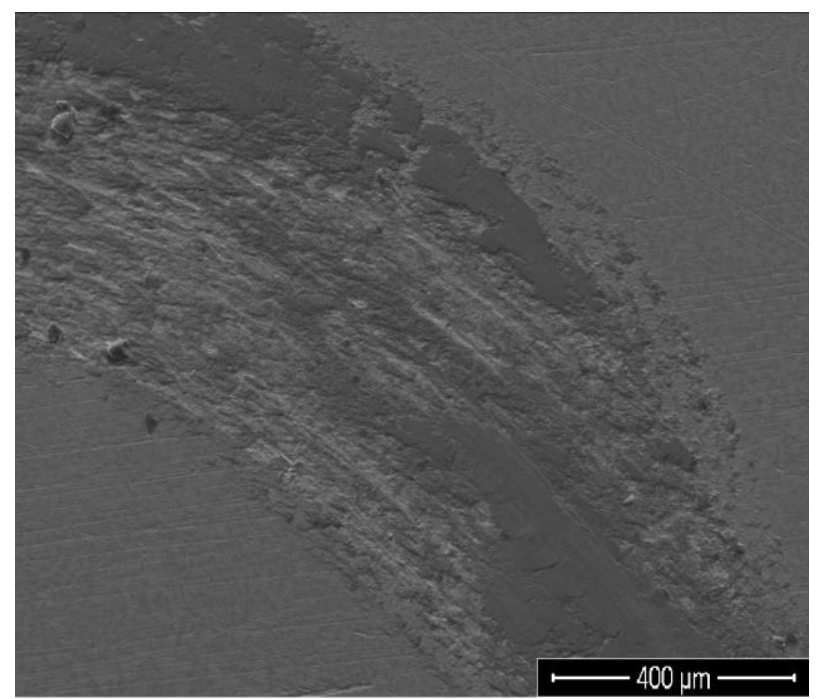

(a)

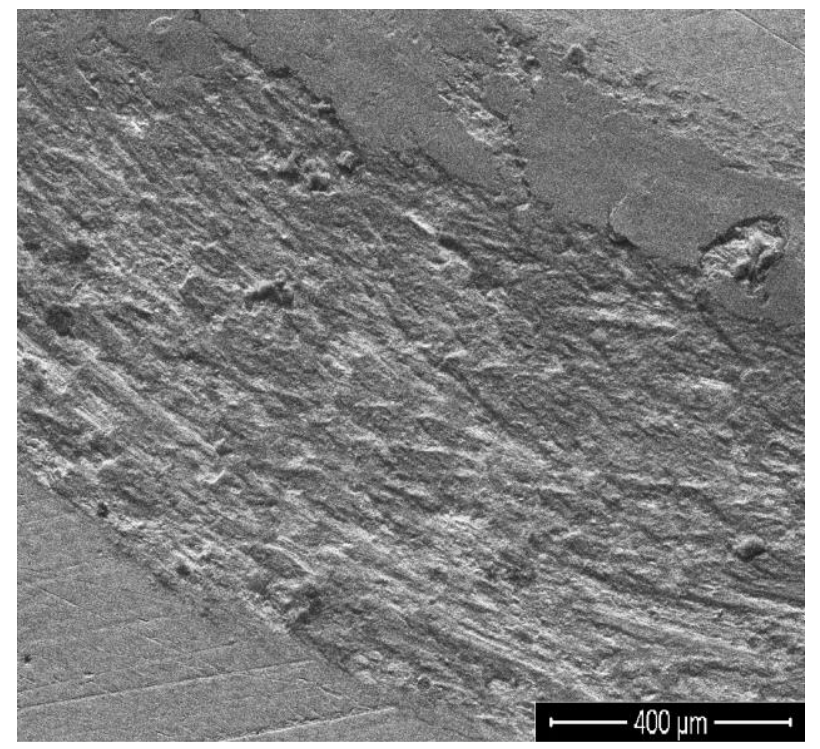

(b)

Fig. 9. Worn surfaces morphology of Alloy (2) under normal load: (a) $50 \mathrm{~N}$, and (b) $100 \mathrm{~N}$.

There were grooves and marks observed in the Fig. 8. Also, there was a materiel transfer from the disc to the pin (alloy) with the augmentation of the normal load and formation of debris (Fig. 8). To analyse the wear mechanism of worn tracks, the alloys have been analysed by EDS analyses.

The Figures 10 and 11 shows the EDS analyses of the worn tracks of the alloy 1 and alloy 2 for the height load $(100 \mathrm{~N})$. The EDS and SEM observations allowed the identification of the type and the nature of wear mechanism, in the Figs. 10a and 10b and Figs. 11a and 11b. From these figures we can see that there is a rough surface with addition of the material on the wear track and the matrix was slightly damaged (Fig. 10a), from the EDS spectrum (Fig. 10b), the presence of the Fer and oxide material do not belong to the pin (alloy1), it is suggested that be a results of tearing the material from the counter face (disc to the pin). Contrary to the Fig. 11a it represents a track wear with some scratches and a removal of material they have abrasive wear. A few presence of the Fer as confirmed in the EDS spectrum (Fig. 11b). The contact between two solids implies a tearing or a displacement of material [19]. At the start of the abrasion tests, the hard compounds are brought directly in contact with the second surface, which means that the phases formed in the alloys is due to the positioning of the hard phases of alloy 1 on the outer surface of the matrix (external layer), leading to a direct exposure of friction on the disc, causing an increase of the friction coefficient that quickly stabilises, resulting in minimal wear.

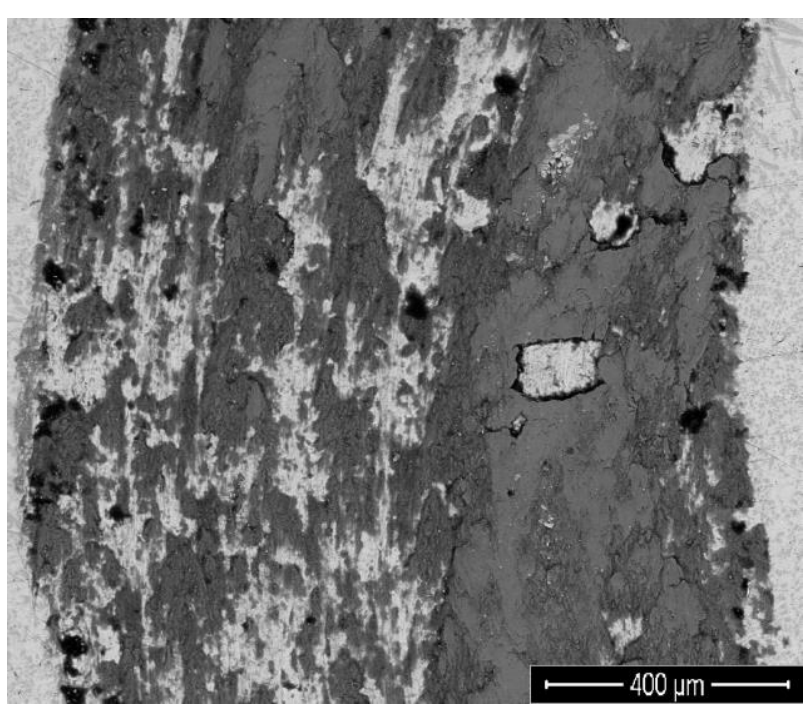

(a)

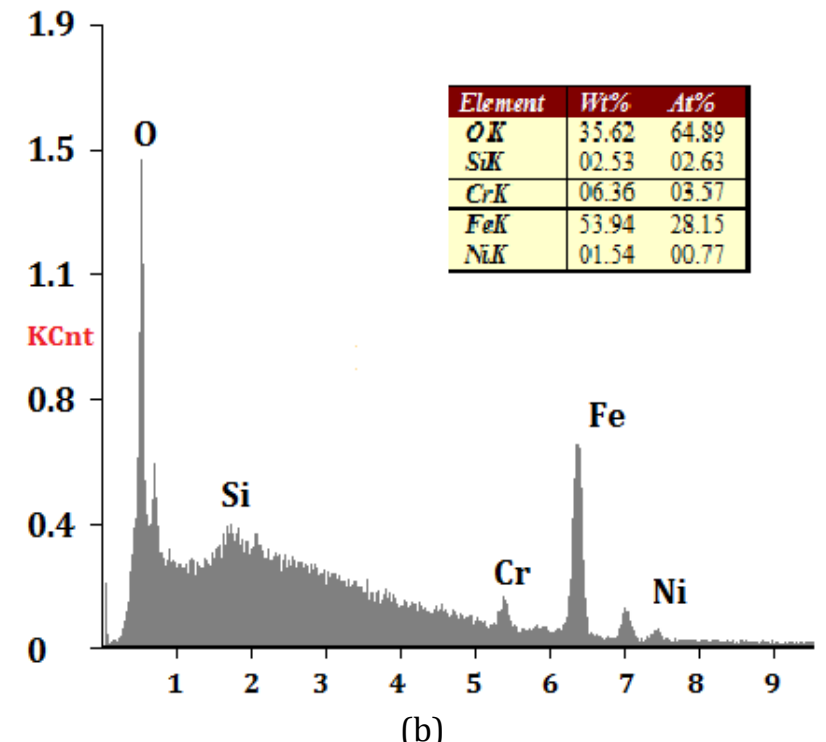

Fig. 10. Wear profile of Alloy 1 in $100 \mathrm{~N}$ : (a) SEM micrograph, (b): EDS spectrum. 


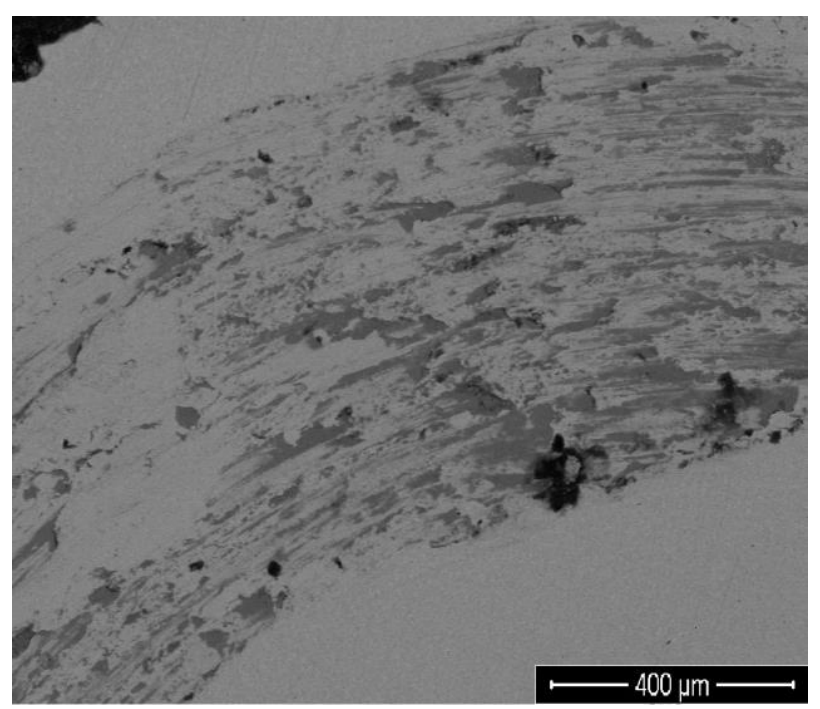

(a)

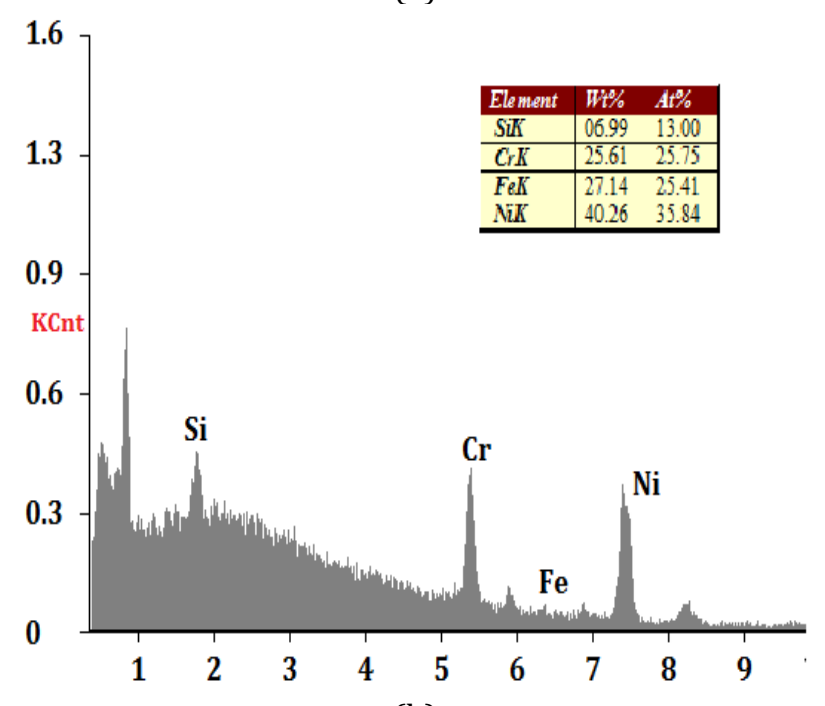

(b)

Fig. 11. Wear profile of Alloy 1 in $100 \mathrm{~N}$ : (a) SEM micrograph, (b): EDS spectrum.

The tribofilms formed at the interface have a stable behaviour while providing sufficient protection against accelerated wear [20]. In contrast to alloy 2 , which is inside the matrix, they are not directly exposed to the disc, which explains a high and stable coefficient of friction and significant wear.

The thickness of the tribofilm formed is not significantly reduced with the increase in load [20].

From this observation, the increase of the normal load affects differently the behaviour of alloys wear caused by ploughing and abrasive actions, due to the resistance of the alloys related to their microstructure as well as the nature and the distribution of the phases formed which is in line with the work of some authors [20-22].

\section{CONCLUSION}

The aim of this study was to show the impact of the normal load applied on the friction and wear behaviour of two types of nickel-based alloys (NI-Cr-B-Si-C-W) using a tribometer and a test bench.

1. We got two different alloys in the quantity of the hard compounds formed, their locations and their morphology.

2. The friction coefficient of alloy 1 increases with the increase of the normal load applied; contrary to the alloy2, their friction coefficient is stable from the beginning of the test.

3. The wear loss is proportional to normal load for both of nickel-based alloys, but we not that the alloy 2 loss more of matter than the alloy 1 despite the stability of its friction coefficient.

4. According to the experiment, the best wear resistance was for the alloys 1 because of their quantity of hard compounds and its perfect location in the matrix of the $\mathrm{Ni}(\gamma)$.

Indeed, we have shown that, the wear resistance of the alloy does not depend on the increase of the normal load but also on the distribution of the hard compounds formed in the matrix of the alloys.

\section{REFERENCES}

[1] M.A. Chowdhury, M. Khalil, D. Nuruzzaman, M. Rahaman, The Effect of Sliding Speed and Normal Load on Friction and Wear Property of Aluminum. International Journal of Mechanical \& Mechatronics Engineering IJMME-IJENS, vol. 11, no. 1 , pp. 53-57, 2011.

[2] B.S. Unlu, H. Durmus, C. Meric, E. Atik, Determination of Friction Coefficient at Journal Bearings by Experimental and by Means of Artificial Neural Networks Method, Mathematical and Computational Application, vol. 9, iss. 3, pp. 399-408, 2004, doi: 10.3390/mca9030399 
[3] A. Elhadi, A. Bouchoucha, W. Jomaa, Y. Zedan, T. Schmitt, P. Bocher, Study of Surface Wear and Damage Induced by Dry Sliding of Tempered AISI 4140 Steel against Hardened AISI 1055 Steel, Tribology in Industry, vol. 38, no. 4, pp. 475-485, 2016.

[4] J.F. Archard, Wear theory and mechanisms. New York, 1980.

[5] V.V. Mishakin, S.N. Verichev, E.N. Razov, Investigation of the Influence of High Hydrostatic Pressure on the Abrasive Wear of Hard-Alloy Materials, Journal of Friction and Wear, vol. 38, no. 4, pp. 286-291, 2017.

[6] J. Wahlström, Y. Lyu, V. Matjeka, A. Söderberg, A pin-on-disc tribometer study of disc brake contact pairs with respect to wear and airborne particle emission, Wear, vol. 384-385, pp. 124-130, 2017, doi: 10.1016/j.wear.2017.05.011

[7] N. Vashishtha, S.G. Sapate, J.S. Gahlot, P. Bagde, Effect of Tribo-Oxidation on Friction and Wear Behaviour of HVOF Sprayed WC-10Co-4Cr Coating, Tribology Letters, vol. 66, no. 56, 2018, doi: 10.1007/s11249-018-1006-1

[8] S. Madhava, A. Chennakesava, Effect of contact time, sliding speed and normal pressure on friction of $A L-S I-M G-F E$ alloy, International Journal of Engineering Sciences and Management, vol. 5, iss. 1, pp. 237-241, 2015.

[9] S. Senhadji, F. Belarifi, F. Robbe-Valloire, Experimental Investigation of Friction Coefficient and Wear Rate of Brass and Bronze under Lubrication Conditions, Tribology in Industry, vol. 38, no. 1, pp 102-107, 2016.

[10] M.M. Matlin, E.N. Kazankin, V.A. Kazankin, Effect of Ratio of Hardness, Load and Roughness Parameters on Approach in Elastoplastic Contact of Rough Surfaces of Flat Parts, Journal of friction and wear, vol. 37, pp. 320-323, 2016, doi: 10.3103/S1068366616040127

[11] A. Behera, A.K. Sahoo. Wear behaviour of $\mathrm{Ni}$ based super alloy, Materials Today: Proceedings, in press, 2020, doi: 10.1016/j.matpr.2020.04.007

[12] S.S. Saleema, M.F. Wania, Tribological characterization of $N 80 \mathrm{~A}$ and 21-4N valve materials against $G G G-40$ seat material under dry sliding conditions at temperatures to $500^{\circ} \mathrm{C}$, Journal of Tribology, vol. 136, iss. 6, p. 20, 2017, doi: $10.1115 / 1.4036273$
[13] G. Khajuria, M.F. Wani, High-Temperature Friction and Wear Studies of Nimonic 80A and Nimonic 90 Against Nimonic 75 Under Dry Sliding Conditions, Tribology Letters, vol. 65, iss. 100, 2017, doi: 10.1007/s11249-017-0881-1

[14] D.M. Nuruzzaman, M.A. Chowdhury, Effect of Load and Sliding Velocity on Friction Coefficient of Aluminum Sliding Against Different Pin Materials. American Journal of Materials Science, vol. 2, no. 1, pp. 26-31, 2012, doi: 10.5923/j.materials.20120201.05

[15] G. Zambelli, L, Vincent, Material and Contacts, a tribological approach. Press polytechniques and Universities of Switzerland, Switzerland, 1998.

[16] T. Sayah, S. Lebaili, G. Marcon. Microstructure and scratching of wear-resistant alloys $\mathrm{Ni}-\mathrm{Cr}-\mathrm{B}$ Si-C-W, Matériaux \& Techniques, vol. 93, no. 7-8, pp. 271-277, 2005, doi: 10.1051/mattech:2005015

[17] T. Sayah, S. Lebaili, G. Marcon, Metallurgical structure and Abrasion Behaviour of $\mathrm{Ni}-\mathrm{Cr}-\mathrm{B}-\mathrm{Si}$ alloys, Matériaux \& Techniques, vol. 93, no. 7-8, pp. 279-287, 2005, doi: 10.1051/mattech:2005016

[18] D. Zhu, X. Zhang, H. Ding, Tool wear characteristics in machining of nickel-based super alloys, International Journal of Machine Tools and Manufacture, vol. 64, pp. 60-77, 2013, doi: 10.1016/j.ijmachtools.2012.08.001

[19] A. Adamkiewicz, J. Drzewieniecki, The Influence of Fuels Quality on Tribological Wear in Slow Speed Diesel Engines, Solid State Phenomena, vol. 252, pp. 1-10, 2016, doi: 10.4028/www.scientific.net/SSP.252.1

[20] S.S. Saleem, M.F. Wani, Effect of load on the retention of tribofilms at the contact interface underdry sliding conditions at $500{ }^{\circ} \mathrm{C}$, Material wissenschaft und Werkstofftechnik, vol. 49, iss. 2, pp. 169-184, 2018, doi: 10.1002/mawe.201700108

[21] G.W. Stachowiak, Wear - Materials, Mechanisms and Practice, New York: Wiley, 2006.

[22] D. Džunić, M. Pantić, S. Mitrović, M. Babić, S. Petrović Savić, A. Đorđević, A. Kokić Arsić, Assessment of tribological behaviour of ZA-27 zinc - aluminium alloy based nanocomposite, Proceedings on Engineering Sciences, vol. 1,no. 1, pp. 145-153, 2019, doi: 10.24874/PES01.01.020 